can be identified in the majority of patients with recurrent VVC. ${ }^{2}$ The intestinal tract has been implicated as a reservoir from which the vagina is repeatedly reinfected. ${ }^{3}$ Nevertheless, simultaneous oral and vaginal treatment has not eliminated recurrences ${ }^{4}$ and vaginitis due to Candida albicans frequently recurred in the absence of positive rectal cultures. ${ }^{5}$

Colonisation of the vagina and oral cavity with Candida albicans may recur after treatment ${ }^{23}$ and an increase in recurrences after cessation of oral treatment has been reported. ${ }^{6}$ The finding of positive penile cultures in $25 \%$ of the male partners of women with VVC may be the consequence of the vaginal infection rather than the cause, since studies failed to demonstrate significant reduction in the rate of reccurent VVC after topical antifungal treatment of the male sex partners.

We investigated the possible correlation between recurrent VVC and the practice of oral sex (fellatio/cunnilingus), considering the practice as the possible vehicle for transferring Candida albicans between the couple.

Investigation was via a retrospective controlled study, whereby female patients in whom three attacks (or more) of VVC had occurred during the previous twelve months were included. The diagnosis of recurrent VVC was made either by the patient's general practitioner, gynaecologist and/or genitourinary medicine physician, on the bases of clinical assessment, microbiological investigations and/or therapeutic cure. Patients with known predisposing factors to candidiasis as discussed previously were excluded.

Twenty seven patients with recurrent VVC as defined earlier, who attended the Department of Genitourinary Medicine at the Coventry \& Warwickshire Hospital were entered into the study. A control group of 27 patients attending the clinic during the same period of time, and without a history of recurrent VVC were matched for age, method of contraception and number of partners (table 1).

Of the 27 patients with recurrent VVC, 25 admitted to the practice of oral as well as vaginal sex while the remaining two admitted to the practice of vaginal sex only (table 2 ).

In the control group, eight patients admitted to the practice of oral as well as vaginal sex and 19 to the practice of vaginal sex only. Statistical

Table 1 The clinical correlates

\begin{tabular}{lll}
\hline & $\begin{array}{c}\text { Study } \\
\text { group }\end{array}$ & $\begin{array}{l}\text { Control } \\
\text { group }\end{array}$ \\
\hline Age range & $18-53$ & $18-44$ \\
Mean & $26 \cdot 96$ & $26 \cdot 11$ \\
Contraception: & 12 patients & 13 patients \\
$\star$ OCP & 4 & 4 \\
Sheath & 3 & 3 \\
Sterilization & 1 & 1 \\
Vasectomy & 1 & 1 \\
Diaphragm & 1 & 1 \\
Hysterectomy & 1 & 4 \\
Cap/Jel & 4 & 24 \\
Nil & 24 & 3 \\
Sex partner: & 3 & \\
Regular & Casual &
\end{tabular}

Table 2 The incidence of sexual practices

\begin{tabular}{llll}
\hline & $\begin{array}{l}\text { Recurrent } \\
\text { VVC }\end{array}$ & $\begin{array}{l}\text { Control } \\
\text { group }\end{array}$ & Total \\
\hline O and V sex & 25 & 8 & 33 \\
V sex only & 2 & 19 & 21 \\
Total & 27 & 27 & 54 \\
\hline
\end{tabular}

Chi square $=19.94$

O: oral, V: vaginal.

analysis of these two groups of patients using the Chi square test revealed a significant difference $(\mathrm{p}<0.001)$ between the two groups, when comparing the incidence of recurrent VVC and oral sex.

We conclude that the practice of oral sex may contribute to recolonisation of the vagina from the oral cavity and hence predisposes to the recurrence of vulvo-vaginal candidiasis. The use of the sheath and/or abandoning the practice of oral sex was associated in one study with a decrease in incidence of recurrences, ${ }^{8}$ which appears to add support to our hypothesis.

A R MARKOS
A A W WADE
M WALZMAN
Department of Genitourinary Medicine,
Coventry E Warwickshire Hospital,
Stoney Stanton Road,
Coventry CV1 4FH, UK

1 Odds FC, Chapter 11. In: Candida and Candidosis 2nd Ed. London, Bailliere and Tindall, 1988.

2 Sobel JD: Management of recurrent vulvo vaginal candidiasis with intermittent ketoconazole prophylaxes. Obstet Gynecol 1985;65:435-40.

3 Bertholf ME \& Stafford MJ: Colonisation of Candida albicans in vagina rectum and mouth. J Family Pract 1983;16: 919-24.

4 Sobel JD: Pathogenesis and epidimeology of the vulvo vaginal candidiasis. Ann NY Acad Sci 1988;544:547-57.

5 Milne JD, Warnock DW: Effect of simultaneous oral and vaginal treatment on the rate of cure and relapse in vaginal candidosis. Br J Venereal Dis 1979;55:302-5.

6 Sobel JD: A Prospective study of the efficacy of maintenance ketoconozole therapy. $N$ Engl $J$ Med 1986;315:1455-8.

7 Sobel JD: Vulvo vaginal Candidiasis. In: King K, Holmes, ed. Sexually Transmitted Diseases. McGraw Hill, New ed. Sexually Transmitied

8 Horwitz BJ, Elderstein S, Ward Lipman C. Sexual transmission of candida. Obstet Gynecol 1987;69:883-6.

Accepted for publication 1 October 1991

\section{Cervical cytology in prostitutes of Bombay (INDIA)}

Sexually transmitted diseases (STDs) form a global health problem since they cause acute and chronic diseases in adults and morbidity in neonates. These infections can be diagnosed by using a number of definitive diagnostic methods beginning from a simple wet smear to sophisticated techniques like DNA hybridisation or electronmicroscopy. However each method has some advantages and disadvantages and many are expensive or technically difficult. Papanicolaou smear is a well established screening technique available for the diagnosis of cervical cancer and intraepithelial neoplasia (CIN). This technique has an additional advantage in the diagnosis of several infections including herpes simplex virus (HSV), human papilloma virus (HPV), Trichomonas vaginalis (TV), anaerobic vaginosis (AV) and candidiasis. ${ }^{1-3}$ It is known in developed countries that the prevalence of CIN is higher in prostitutes compared with the 
Table Papanicolaou smear pattern in 515 prostitutes

\begin{tabular}{lrl}
\hline Cytology & No & $\%$ \\
\hline Negative & 160 & $(31.0 \%)$ \\
Inflammation & 252 & $(48.9 \%)$ \\
CIN I & 60 & $(11 \cdot 7 \%)$ \\
CIN II & 16 & $(3.2 \%)$ \\
CIN III & 7 & $(1 \cdot 4 \%)$ \\
Squamous cell carcinoma & 1 & $(0 \cdot 2 \%)$ \\
Trichomoniasis & 50 & $(9 \cdot 7 \%)$ \\
Candidiasis & 22 & $(4 \cdot 3 \%)$ \\
Anaerobic vaginosis & 188 & $(36.5 \%)$ \\
HSV infection & 11 & $(2 \cdot 1 \%)$ \\
HPV infection & 82 & $(15.9 \%)$ \\
\hline
\end{tabular}

general population. ${ }^{4}$ Prostitutes also commonly suffer from various STDs. There are very few reports on the prevalence of CIN in cervical smears from prostitutes in developing countries $^{5}$ and none from India. Our experience in family planning (FP) clinics has shown that the Papanicolaou smear may be a valuable technique in the diagnosis of many STDs. ${ }^{6}$ We report the results in 515 prostitutes from Bombay. All women were in the age group of 20 to 30 years with a coital frequency of 28-36 per week with multiple sexual partners. The majority of them were asymptomatic $(92 \%)$ and had come for a health check up. The overall prevalence of one or more STDs by cytology was $51 \cdot 2 \%(264 / 515)$. Out of these a single STD was observed in $63.7 \%$ and multi- ple STDs in $36.3 \%$ of cases. The smear pattern and the prevalence of individual STDs are given in the table.

Cervical cytology may be a useful screening test for STDs in developing countries because other tests are usually not available or are expensive and resources are limited. However, cytology cannot substitute other definitive diagnostic methods if available.

$$
\begin{array}{r}
\text { BAPURAO N MALI } \\
\text { JAYASHREE V JOSHI } \\
\text { Institute for Research in Reproduction (ICMR), } \\
\text { Parel, Bombay 400 012, India } \\
\text { GEETA G BHAVE } \\
\text { USHA D WAGLE } \\
\text { Sheth GS Medical College, } \\
\text { Parel, Bombay 400 012, India }
\end{array}
$$

1 Thin RNT, Atia W, Parkar JVJ, Nicol CS, Canti G. Value of Papanicolaou stained smears in the diagnosis of trichoPapanicolaou stained smears in the diagnosis of trichomoniasis, candidiasis and cervical herpes simplex virus

2 Kiviat NB, Paavonen JA, Brockway J, et al. Cytologic manifestations of cervical and vaginal infections. 1 Epithelial and inflammatory cellular changes. JAMA 1985;253:989-96.

3 Meisels A, Fortin R. Condylamotous lesions of the cervix and vagina: 1. Gytologic pattern. Acta Cytol 1976;20 505-9.

4 Briggs RM, Holmes KK, Kiviat NB, Barkar E, Eschenback DA, De Jong $R$. High prevalence of cervical dysplasia in STD clinic patients warrants routine cytologic screening. Am J Public Health 1980;70:1212-4.

5 Abeyewickreme I. Cervical cytology screening in sexually transmitted disease clinic for the first time in Sri Lanka. transmitted disease clinic for the
Genitourin Med 1989;65:98-102.

6 Joshi JV, Mali BN, Hazari KT, et al. Cytological manifestations of sexually transmitted diseases. J Obstet Gynecol India (In press).

\section{Antibiotic prophylaxis for cold coagula- tion of the cervix?}

Intravaginal triple sulphonamide cream (Sultrin-Cilag Ltd) has previously been advocated as reducing postoperative complications and symptoms following cervical surgery. ${ }^{1-3}$ This had been routinely prescribed following cold coagulation of the cervix in this department and accounted for $32 \%$ of the department antimicrobial budget. Since no evidence of the efficacy of Sultrin in this particular setting was available and some patients had reported the treatment as messy and unpleasant, a randomised, prospective trial was carried out comparing intravaginal Sultrin with oral metronidazole and no treatment.

One hundred and ten patients undergoing cold coagulation of the cervix were recruited from the colposcopy clinic at the Nottingham Department of Genitourinary Medicine. These patients had had abnormalities ranging from wart virus changes to CIN 3 diagnosed from colposcopically guided punch biopsy 2 or more weeks prior to treatment.

After informed consent was obtained standard screening tests for sexually transmitted diseases ${ }^{4}$ were carried out and cold coagulation was performed under lignocaine local anaesthesia. Patients were then randomly allocated to either: No treatment; metronidazole $200 \mathrm{mgs}$ three times per day for seven days; or Sultrin cream applied intravaginally twice daily for seven days.

Six patients were excluded because of infection found in the entry screening tests and 89 who returned for review between 14 and 35 days were included in the analysis. At this time symptoms after cold coagulation and cervical appearance were noted. Results are shown in the table.

Statistics were by Chi squared analysis and Fishers exact test.

Whilst no differences were seen between the

Table Symptoms and signs on review

\begin{tabular}{lllll}
\hline & \multicolumn{2}{l}{ Treatment Group } & & \\
\cline { 2 - 5 } & Metronidazole & Sultrin & No treatment & \\
\hline Total number of patients & 28 & 33 & 28 & $\mathrm{p}=\mathrm{NS}$ \\
Bacterial vaginosis at entry & 7 & 7 & 8 & $\mathrm{p}=\mathrm{NS}$ \\
Discharge for <6 Days & 5 & 8 & 6 & \\
7-13 Days & 5 & 18 & 27 & $\mathrm{p}=0.025$ \\
>14 Days & 18 & 23 & 1 & $\mathrm{p}=0.013$ \\
Bleeding for <6 Days & 23 & 10 & 22 & \\
>7 Days & 5 & 27 & & \\
\hline
\end{tabular}

